\title{
Design of Nanomodified Intumescent Polymer Matrix Coatings: Theory, Modeling, Experiments
}

\author{
Alexandr Evstigneev, Vladimir Smirnov ${ }^{*}$ and Evgenij Korolev \\ Moscow State University of Civil Engineering, Yaroslavskoe shosse. 26, Moscow, 129337, Russia
}

\begin{abstract}
Thermoset-based polymer matrix composites are widely used for production of intumescent fire protective coatings; many operational properties of such coatings can be further enhanced by means of nanoscale layers between matrix and disperse phases. The dependence between temperature of processing and temperature of glass transition of thermosetting matrix allows to produce gradient of glass transition temperature along the depth of the coating and lower exfoilation of char residue from steel substrate. In the present article we have offered the novel design scheme for such coating. Several results of laboratory and numerical experiments that are within the framework of the offered scheme are also presented. Application of the offered scheme allows to develop efficient fire protective coatings in purposely and precisely controlled manner.
\end{abstract}

\section{Introduction}

Current construction industry is in immense need of polymer matrix composites (PMC) with unique complexes of operational properties [1]. Furthermore, it is often required for such composites to possess not only the desired operational properties during normal operation, but also to provide protection of underlying construction in case of hazardous events, notably fires [2-5].

One of the modern trends in fire protection consists in application of intumescent fire protective (IFP) coatings. During fire such coating expands in volume in at least an order of magnitude, forming highly porous char residue with low thermal conductivity, thus preventing quick heat transfer that leads to loosing the structural strength by underlying construction [6-10].

Common way to create PMC for IFP coating is by means of special disperse phases, e.g. ammonium polyphosphate (APP), pentaerythritol (PET) and others [11-14]. Relatively new and quite prospective intumescent admixture is the expandable graphite (EG) that can be formed as result of treatment of flake graphite with mixture of acids (sulfuric and others) and some oxidizing agents (potassium permanganate etc.) [15-19].

Obviously, proper decomposition of R\&D task is the key factor for successful design of PMC for IFP coating. The overall goal of every R\&D in construction is extremely apparent: to reduce total cost on entire life cycle (while keeping safety of operation and similar

\footnotetext{
*Corresponding author: smirnov@ nocnt.ru
} 
characteristics at predefined levels). Reformulating such an objective in terms of material science and construction technology is, unfortunately, a most problematic.

There are numerous fields of science (mostly mathematics, probability theory and applied statistics) that deal with application of analytical methods to problem solving and making decisions in the real world: systems analysis, operations research, control theory, multivariate analysis, design of experiments (DoE) and so forth.

Objective of the present work is to develop novel design scheme for IFP coating while: a) staying within framework of the mentioned disciplines; b) making use of knowledge that is already available in material science.

\section{Prior work}

\subsection{Systems analysis}

Systems analysis is the study of the system and its components that serves as tool for description of early phases of development and is driven by the business concerns of "owners" and "users" of the system [20,21]. Strictly speaking, operations research is just an important subdomain of systems analysis; however, since it mostly deals with optimization, simulation and other particular techniques, it will be considered later. Systems analysis should be used as a primary tool when selecting and ranging both subgoals of $\mathrm{R} \& \mathrm{D}$ and control variables that vary during the course of development process.

The cycle consisting of the principal stages of $R \& D$ that involved systems analysis is presented in [21]. This cycle comprises of nine nodes: "scope definition", "problem analysis", "requirements analysis", "design analysis", "physical design and integration", "construction and testing", "installation and delivery", "system operation and maintenance". System "owners" and "users" ("business community", ninth node) acts as a link that closes the cycle between "system operation" and "scope definition". All chains of the cycle are connected to the inner node that represents the system under design.

The full cycle is out of scope in this work; our purpose is only to interpret and concretize stages from "scope definition" to "physical design" in the context of IFP coating made of PMC. Concerning R\&D in material science, some results for the first and second stages are already known [22-25].

One of the approaches toward materials design has been demonstrated in [26]. The approach is based on combinatorial materials research and integrates workflow steps "theory", "modeling and data storage"; "synthesis, characterization and testing"; "data management"; "data mining", which also form a closed loop. It was shown that the proposed design scheme is of innovative power and efficiency.

\subsection{Operations research: DoE, optimization and multivariate analysis}

Whereas systems analysis is a tool that allows to represent the R\&D as a whole, operations research is an area that provides numerous particular methods and techniques that should be applied at different staged of development cycle. The "physical design and integration" is the stage of most interest.

Design of experiments (mathematical theory of experiment) [27-29] is a discipline that should be used for planning, carrying out, processing and interpretation of numerical, laboratory and field experiments. First one of the four mentioned stages reduces to the choice of regression model that should describe the system according to the objective of experiment; second and third stages are semi-formal; fourth stage, interpretation, should be carried out in terms of the research field. Within the entire R\&D cycle, DoE processes 
make closed sub-cycles (each one closes by the link from interpretation to the first stage). Methods of single- and multivariate [30] optimization (search for local and global extrema, clustering and so on) are usually applied during interpretation of experimental results. Multivariate techniques consider several random variables as a single entity and produce overall result in form of smaller set of uncorrelated variables or even single variable [31].

\subsection{Multiscale modeling}

There is a technique within the "physical design and integration" stage which needs additional attention. It is the numerical modeling.

In general, term "modeling" (developing and further examination of the representation of system under investigation) applies to quite different techniques. These techniques can be separated by the properties of interest (type of similarity). For example [32], construction of the regression model (finding the parameters of analytic representation) in DoE cycle can be called "regression modeling" or "statistical modeling".

Numerical modeling is a branch of mathematical modeling. As a rule, in a science of construction materials we are interested in chemical (lower spatial scales, from atomistic to nanostructure), physical-chemical (from nano- to macrostructure), physical and geometric (macrostructure of material and properties of entire construction) similarities. Due to different types of similarities and taking into account the necessity to jointly use the results that are obtained on different levels, it is productive to employ so-called multiscale modeling [33-35].

\section{Scope definition, problem analysis and requirements analysis}

The scope of the problem (passive fire protection of steel constructions) and problem analysis were already briefly discussed in Introduction. There are at least to well known problems with construction steel. First problem is low corrosion resistance; second one is that at high temperatures elastic modulus of steel lowers down to unacceptable levels causing failures of constructions.

Thus, it is required for the coating:

a) to provide corrosion protection during normal operation, including good adhesion to steel, high barrier properties (low permeability), high water and chemical resistance, low weathering;

b) to provide thermal insulation during fire, including high expansion factor (relation of the coating volume to char residue), integrity and absence of exfoliation from steel.

If properly designed, PMC with epoxy matrices can fulfill all above requirements [5]. Selection of the thermosetting matrix material introduces additional factors that can be taken into consideration during problem analysis.

1. Significant expansion of PMC without integrity lost can proceed only if temperature of material is above glass transition $T_{g}$. This should be kept in mind when selecting intumescent phases.

2. Glass transition temperature of PMC depends both on formulation (type and volumetric ratio of resin and cross-linking agent) and temperature regime of hardening. By varying formulation, it is possible to control $T_{g}$ in block. And what is most important, further thermal processing of the coating allows to form the gradient of $T_{g}$ along the depth of the coating.

Properties of PMC as a disperse system can also be controlled by many well known factors, including type and volumetric content of the fillers. 
Recent developments in various areas of nanotechnology show significant promise in addressing many of challenges faced by the construction industry ranging from structural strength enhancement to self-cleaning [1,36-39] and biocidal properties [40]. In particular, incorporating nanoparticles or nanolayers into polymer matrix coatings and thin films can provide enhanced performance and additional functionalities [1]. Since successful application of IFP coatings can be hampered by their susceptibility to damage by surface wear [41], resistance to abrasion is an important characteristic. This characteristic, together with adhesion and barrier properties, can be enhanced by nanolayers formed at the phase boundary between matrix and disperse phases. The known way to form such layers is to preprocess the disperse phase with solution of silane coupling agent; processing of substrate can also be useful [42].

\section{Design analysis}

Concerning the design graph that is presented in [21], it should also be noted that in real $R \& D$ there will be also directed interconnects from any later to any former node (figure 1).

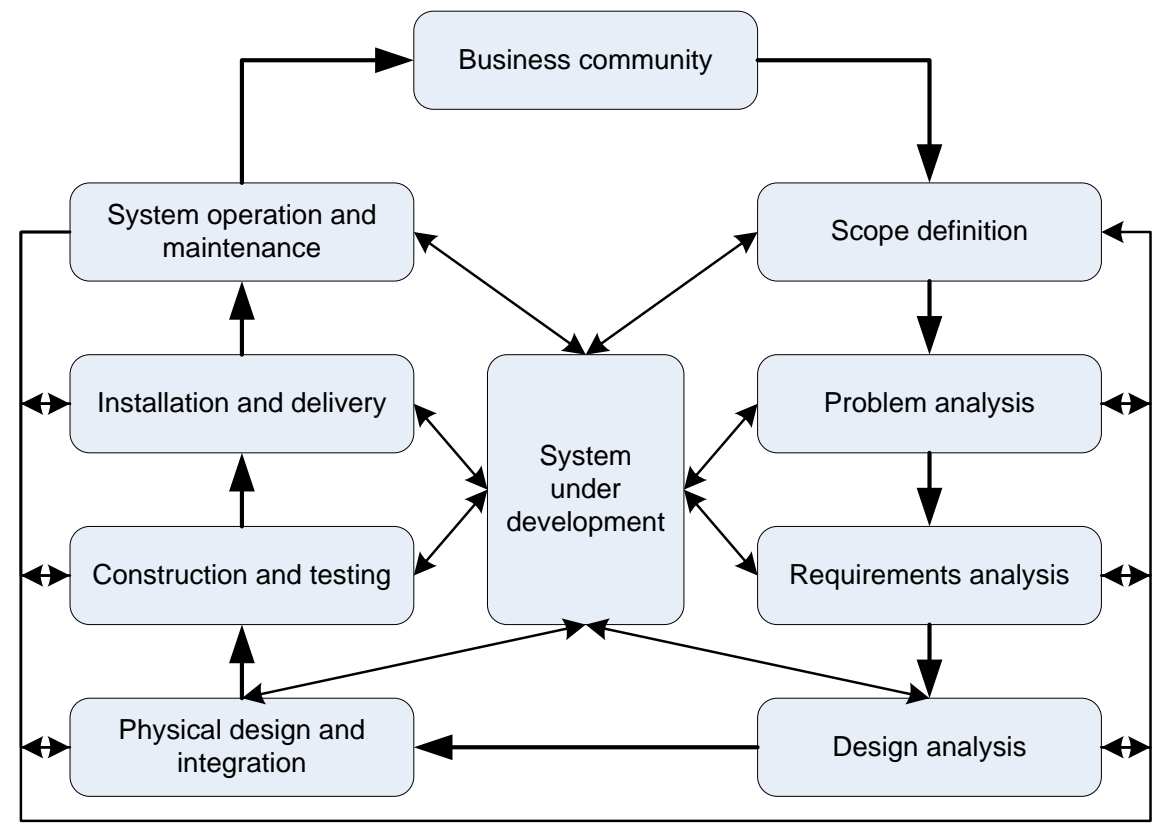

Fig. 1. Full R\&D graph

This design analysis stage of $R \& D$ cycle is the distinct target in the present work; in particular, this stage involves decomposition of "Physical design and integration" stage. The proposed design graph of "Physical design" stage is presented on figure 2.

There can be separated two weakly interconnected branches of design process. The first branch "PMC" is mostly related with PMC in block (e.g., mostly with materials and formulations). Modeling stage (1.1 on figure 2 ) is required to determine the parameters of complex process that will be implemented to form nanoscale interlayer on the phase boundaries. Next stage consists of selection of formulations that will be examined. According to the requirements summarized in previous section, examination consists in laboratory tests for adhesion, barrier properties, high water and chemical resistance and 
weathering (stages 1.3 and 1.4). On the whole, there are no novel stages in the first branch; such stages, though, present in the second one.

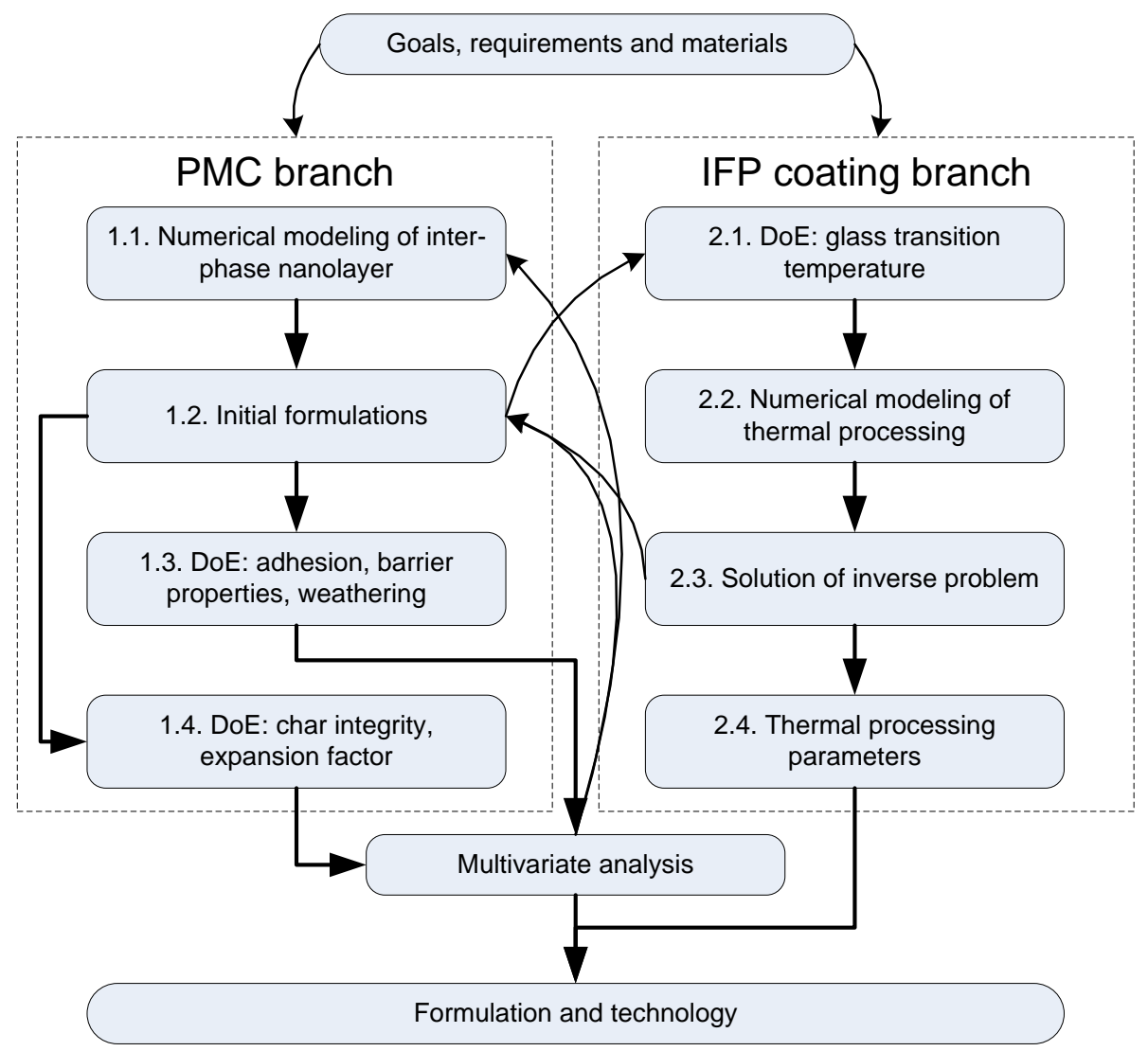

Fig. 2. Graph of "Physical design" stage

The second branch, as it follows from its title "IFP coating", is mostly related with IFP coating (e.g., mostly with technology). This branch can be started as soon as initial formulation is defined (stage 1.2 in PMC branch).

The net effect of all operations in the second branch consists in the producing of gradient coating by altering the glass transition temperature along the depth. To achieve this, we offer the scheme that combines DoE and numerical experiments. In accordance to the design objectives, requirements and extra considerations that have been summarized above, the following materials during can be used: DER 330 epoxy resin hardened by 9210 amine adduct, amount of hardener is $65 \%$ by mass, $24 \mathrm{~h}$ at room temperature; EG and APP as disperse phases; (3-aminopropyl)triethoxysilane as a coupling agent.

Firstly, for the formulations from stage 1.2 the experimental dependencies between temperature of processing and resulting glass transition temperature are obtained. The example of such dependence is presented on figure 3 . 


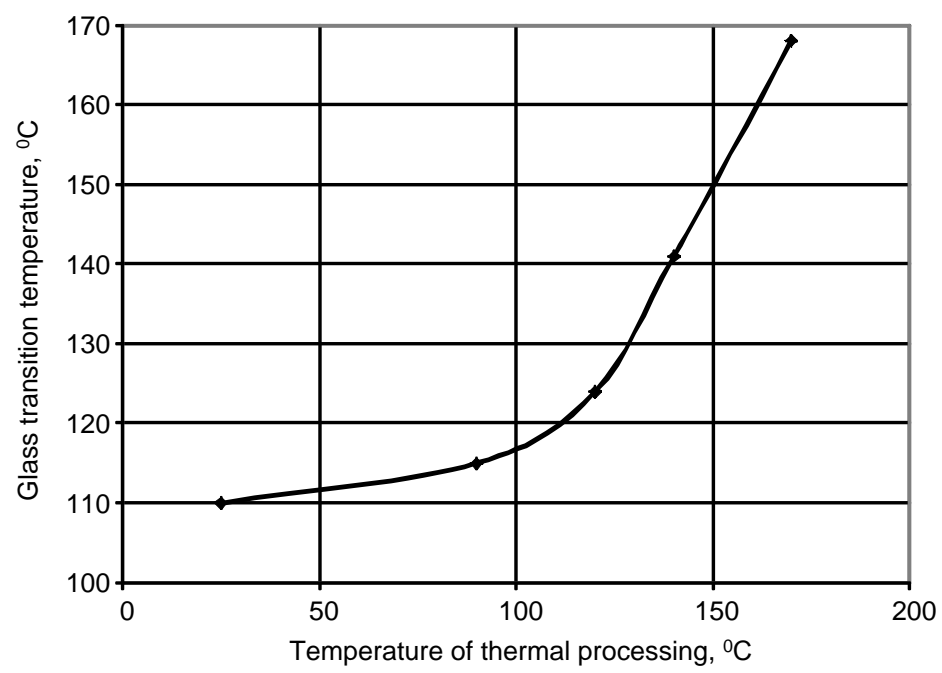

Fig. 3. Experimental dependence between temperature of processing and temperature of glass transition

On the next stage (stage 2.2) in the branch there will be modeling of transient thermal fields in IFP coating during thermal processing. The modeling task is the multi-field problem of stationary computational fluid dynamics (forced convection) and transient conjugate heat transfer. There are three subdomains in computation domain: fluid subdomain (stream of hot air and surrounding air at room temperature) and two solid subdomains (coating and steel substrate). Boundary conditions for fluid subdomain are presented on figure 4. Several results for air domain are presented on figures 5-7 (radius of nozzle outlet is $10 \mathrm{~mm}$, air velocity at the outlet is $30 \mathrm{~m} / \mathrm{s}$, distance between outlet and coating is $75 \mathrm{~mm}$, SST turbulence model).

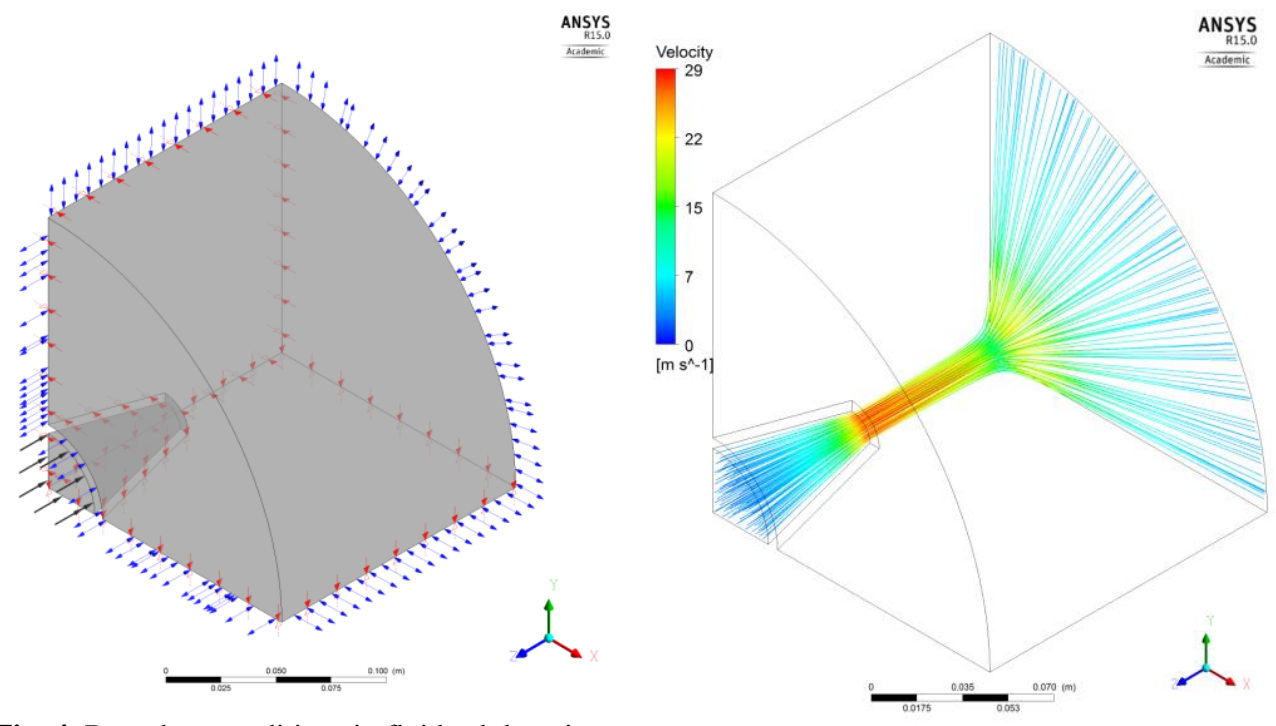

Fig. 4. Boundary conditions in fluid subdomain (one quarter, symmetry for bottom and back)

Fig. 5. Air flow 


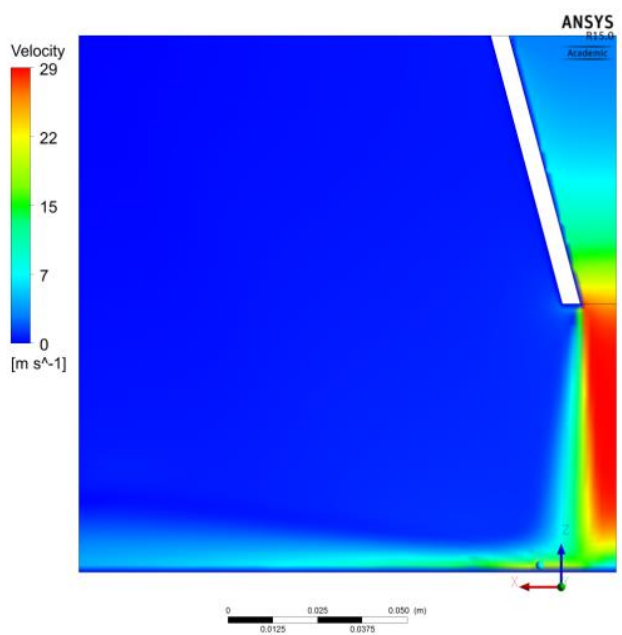

Fig. 6. Modulus of air velocity in section

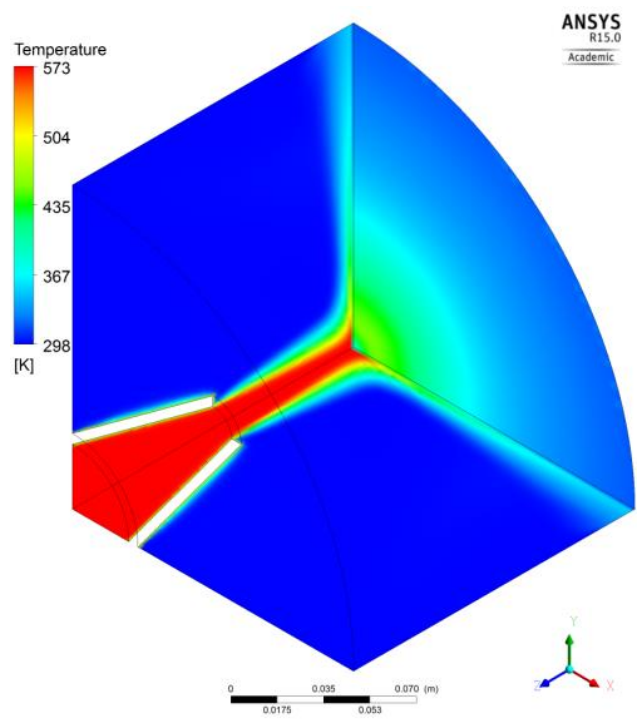

Fig. 7. Temperature in the air domain and boundary surface of coating

At the next two stages (2.3 and 2.4) the inverse problem of determination the desired thermal processing parameters on the base of simulation results will be solved.

The last stage is multivariate analysis. The optimal set of control variables (formulation and technology) will be obtained.

\section{Summary and conclusion}

It the present work we have offered the novel design scheme for IFP coating made of nanomodified epoxy PMC.

The novelty of the offered design scheme consists in new combination of experimental and numerical methods that allows to form the gradient of glass transition temperature along the depth of the coating. The precondition is the dependence between temperature of processing and temperature of glass transition of thermosetting matrix. Gradient of glass transition temperature contributes homogeneity of expanded char residue and can prevent its exfoilation from steel substrate.

To exemplify the design scheme, we have presented several results of laboratory experiments (dependence between temperature of processing and temperature of glass transition) and numerical modeling (flow of hot air and temperatures during processing of the coating).

Application of the offered design scheme allows to develop efficient IFP coatings in purposely and precisely controlled manner.

This work is supported by Ministry of Education and Science of Russian Federation, project "Theoretical and experimental models of functional composites based on prime nanomaterials" $7.6250 .2017 / 8.9$

\section{References}

1. M.J. Hanus, A.T. Harris, Progress in Materials Science, 58 (2013) 
2. A.A. Askadsky, V.A. Ushkov, V.A. Smirnov, Proceedings of the International Conference on Advanced Materials, Structures and Mechanical Engineering (ICAMSME 2015), Incheon, South Korea (2016)

3. A.A. Askadsky, V.A. Ushkov, V.A. Smirnov, V. Voronin, Solid State Phenomena, 871 (2016)

4. V.A. Ushkov, A. Kopytin, V.A. Smirnov, L. Alimov, Procedia Engineering, 165 (2016)

5. V. Smirnov, E. Korolev, MATEC Web of Conferences, 193 (2018)

6. N.R. Baddoo, Journal of Constructional Steel Research, 64 (2008)

7. T.C.H Liu, M.K. Fahad, J.M. Davies, Journal of Constructional Steel Research, 58 (2002)

8. S.R. Najjar, I.W. Burgess, Engineering Structures, 18 (1996)

9. M. Feng, Y.C. Wang, J.M. Davies, Fire Safety Journal, 38 (2003)

10. F. Wald, L. Simões da Silva, D.B. Moore, T. Lennon, M. Chladná, A. Santiago, M. Beneš, L. Borges, Fire Safety Journal, 41 (2006)

11. S. Chiu, W. Wang, Polymer, 39 (1998)

12. M. Jimenez, S. Duquesne, S. Bourbigot, Thermochimica acta, 449 (2006)

13. S. Bourbigot, S. Duquesne, Journal of Materials Chemistry, 17 (2007)

14. B. Pani, S. Sirohi, D. Singh, American Journal of Polymer Science, 3 (2013)

15. Z. Wang, E. Han, W. Ke. Corrosion Science, 49 (2007)

16. S. Ullah, F. Ahmad, P.S.M. Megat-Yusoff, N.H. Azmi, Journal of Applied Sciences, $11(2011)$

17. Y. Li, S. Zou, J. Zhou, C. Yang, H. Zou, M. Liang, W. Luo, Journal of Applied Polymer Science, 131 (2014)

18. S. Ullah, F. Ahmad, A.M. Shariff, M.A. Bustam, AIP Conference Proceedings, 1621 (2015)

19. J. Li, X. Mo, Y. Li, H. Zou, M. Liang, Y. Chen, Polymer Bulletin, 75 (2018)

20. N.N. Moiseev, Mathematical Goals of System Analysis (NAUKA, Moscow, 1981) [in Russian]

21. J.L. Whitten, L.D. Bentley, System Analysis and Design Methods (McGraw-Hill, New York, 2007)

22. A.M. Danilov, I.A. Garkina, E.V. Korolev, Stroitel`nye Materialy, 7 (2006) [in Russian]

23. Ju.M. Bazhenov, A.M. Danilov, I.A. Garkina, E.V. Korolev, Regional Architecture and Engineering, 1 (2006) [in Russian]

24. A.M. Danilov, I.A. Garkina, E.V. Korolev, Regional Architecture and Engineering, 1 (2008) [in Russian]

25. I.A. Garkina, A.M. Danilov, E.V. Korolev, Vestnik MGSU, 2 (2011) [in Russian]

26. R. Iden, W. Schrof, J. Hadeler, S. Lehmann. Macromolecular Rapid Communications, 24 (2003)

27. V.V. Nalimov, Theory of the Experiment (NAUKA, Moscow, 1971) [in Russian]

28. V.V. Nalimov, T.I. Golikova, Logical Bases of the Design of Experiments (METALLURGIYA, Moscow, 1981) [in Russian]

29. W.G. Cochran, Planning and analysis of observational studies (Wiley, New York, 1983)

30. I.A. Garkina, A.M. Danilov, E.V. Korolev, V.A. Smirnov, Stroitel’nye Materialy, 8 (2006) [in Russian]

31. J.E. Jackson, A User's Guide to Principal Components (Wiley, New York, 1991)

32. V.A. Gladkikh, E.V. Korolev, V.A. Smirnov, I. Sukhachev, Procedia Engineering, 165 (2016)

33. E.V. Korolev, V.A. Smirnov, Advanced Materials Research, 746 (2013) 
34. E.V. Korolev, A.S. Inozemtcev, A.V. Evstigneev, Key Engineering Materials, 683 (2016)

35. V.A. Smirnov, A.V. Evstigneev, E.V. Korolev, MATEC Web of Conferences, 106 (2017)

36. J. Lee, S. Mahendra, P.J.J. Alvarez, ACS Nano, 4 (2010)

37. W. Zhu, P.J.M. Bartos, A. Porro, Materials and Structures, 37 (2004)

38. A.S. Inozemtcev, IOP Conference Series: Materials Science and Engineering, 71 (2015)

39. A.S. Inozemtcev, E.V. Korolev, V.A. Smirnov, Structural Concrete, 18 (2017)

40. S.S. Kumar, International Journal of Engineering and Applied Sciences, 2 (2015)

41. F. Dietsche, Y. Thomann, R. Thomann, R. Mulhaupt, Journal of Applied Polymer Science, 75 (2000)

42. J. Jang, E.K. Kim, Journal of Applied Polymer Science, 71 (1999) 